\title{
Wall Incident Heat Flux Distributions Resulting from an Adjacent Fire
}

\author{
G. BACK, C. BEYLER and P. DiNENNO \\ Hughes Associates, Inc. \\ 6770 Oak Hall Lane, Suite 125, Columbia, MD 21045, USA \\ P. TATEM \\ Naval Research Laboratory \\ Washington, DC 20375, USA
}

\begin{abstract}
Incident wall heat flux distributions have been measured for square propane burner fire sources placed against the wall. Peak heat fluxes of $40-120 \mathrm{~kW} / \mathrm{m}^{2}$ were measured for heat release rates of $50-500 \mathrm{~kW} / \mathrm{m}^{2}$ and burner edge lengths of $0.28-0.7 \mathrm{~m}$. Peak heat fluxes were found to be a strong function of heat release rate but were insensitive to flame aspect ratio or burner size. Correlations of the data were developed to represent the measured flux distributions. These correlations are intended for use in wall flame spread modeling.
\end{abstract}

KEYWORDS: heat flux, wall fires, flame heat transfer

\section{INTRODUCTION}

Over the past decade, a great deal of work has been done in the area of flame spread on vertical surfaces ${ }^{1-8}$ and the role of wall covering materials in room fire development ${ }^{9-}$ 15. This work has been hampered by a lack of detailed characterization of flames exposing and igniting the wall material. Most commonly used wall materials cannot be casually ignited with small ignition sources. Rather, they require external heating from an adjacent fire such as a waste basket or furniture item.

Most investigations of upward flame spread have used line burners as ignition sources. The heat flux distribution from such line burners has been characterized by Hasemi ${ }^{4}$ and has been shown to be very similar to heat flux distributions from wall flames themselves $^{17}$. Peak heat fluxes in the $20-30 \mathrm{~kW} / \mathrm{m}^{2}$ are typical. Thus, most of the work to date has focused on the problem of given an initial burning section will the flame 
extend vertically and how fast is the spread. Given the very thin nature of line flames and flames on wall surfaces, it is to be expected that adjacent flame ignition sources would provide higher heat fluxes than a line or wall section source. Wall materials, which do not propagate flame vertically for a line fire source, may indeed spread flame for an adjacent item ignition source.

The distribution of the incident heat flux from such ignition sources has been studied by Williamson et al. ${ }^{15}$ and by Kokkala ${ }^{16}$ in a comer configuration and limited measurements have been made by Mizuno and Kawagoe ${ }^{18}$ for a wall configuration. These investigations confirm that heat fluxes from such adjacent item ignition sources are much higher than line or wall flames. Williamson et al. ${ }^{15}$ observed heat fluxes of up to 60 $\mathrm{kW} / \mathrm{m}^{2}$, Kokkala ${ }^{16}$ observed heat fluxes up to $115 \mathrm{~kW} / \mathrm{m}^{2}$, and Mizuno and Kawagoe ${ }^{18}$ observed fluxes as high as $100 \mathrm{~kW} / \mathrm{m}^{2}$.

Based on the available data, it is clear that an assessment of the performance of a wall material in a fire scenario of interest must include a characterization of the heat fluxes provided by the flame ignition source. In this work, the incident heat flux distributions from square burners to an adjacent wall were measured for fires sources ranging from 0.3 to $0.7 \mathrm{~m}$ on an edge and heat release rates from 50 to $500 \mathrm{~kW}$. This is the range of likely flame ignition sources in many applications.

\section{EXPERIMENTAL APPARATUS AND PROCEDURES}

The experimental apparatus is shown in Figure 1. The wall was $2.4 \mathrm{~m}(8 \mathrm{ft})$ high and $5 \mathrm{~m}(16 \mathrm{ft})$ long gypsum wall board over a steel framing system. The test fires were produced using square propane fueled sand burners. The edge lengths of the burners used were $0.28,0.37,0.48,0.57$, and $0.7 \mathrm{~m}$.

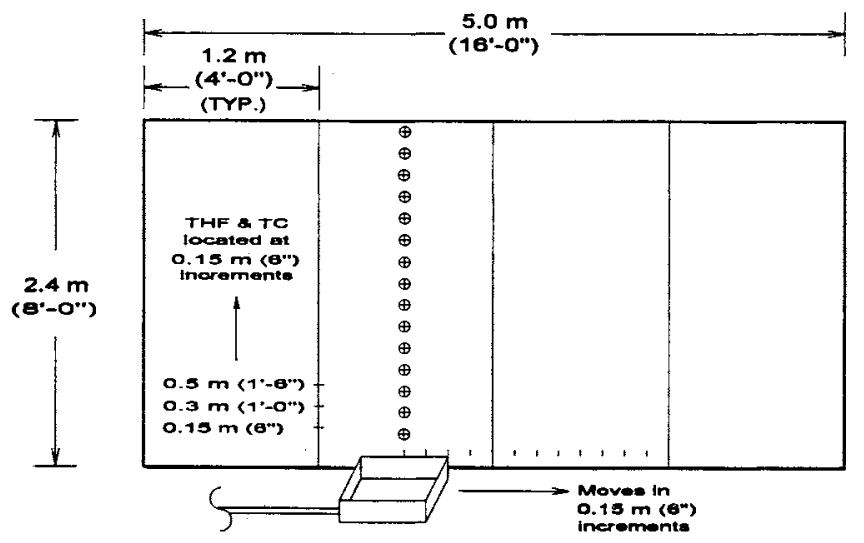

FIGURE 1. Experimental setup for wall heat flux measurements. Instruments were fixed, and the burner source was translated to develop flux maps. 
Eight Medtherm total heat flux (THF) transducers were used in these tests with ranges from 55 to $220 \mathrm{~kW} / \mathrm{m}^{2}$, depending on the transducer location. These transducers were installed flush with the wall surface at various heights selected based on the calculated flame height for a given test. A vertical array of thermocouples was installed beside the total heat flux array. Thermocouples were inconel-sheathed type $\mathrm{K}$ and were installed approximately $1.25 \mathrm{~cm}(0.5 \mathrm{in}$.) from the wall surface. Since the THF probes were subjected to prolonged direct flame exposure, prior to the start of testing each day, the calibration of the THF probes was checked.

Test conditions used in this investigation included burner sizes from $0.28-0.7 \mathrm{~m}$ and heat release rates of $50-500 \mathrm{~kW}$. Flame aspect ratios (flame height/burner edge length) ranged from approximately 0.5 to 4 (Test 2, Table 1 ). The specific test conditions are included in Table 1 . Measurements were made with the burner centered on the vertical heat flux meter array and at $0.15 \mathrm{~m}$ increments away from the centerline. Data were collected using a PC-based system for a period of five minutes in each burner location. Videotape recordings were made of each test to allow determination of the flame height.

TABLE 1. Test Conditions and Flame Height

\begin{tabular}{|c|c|c|c|c|}
\hline $\begin{array}{c}\text { Test } \\
\text { Number }\end{array}$ & $\mathrm{Q}(\mathrm{kW})$ & $\mathrm{D}(\mathrm{m})$ & $\begin{array}{c}\text { Videotape Flame } \\
\text { Height }(\mathrm{m})\end{array}$ & $\begin{array}{c}\text { 500 } \\
\text { Height }(\mathrm{m})\end{array}$ \\
\hline \hline 1 & 53 & 0.28 & 0.79 & 0.78 \\
\hline 2 & 56 & 0.70 & 0.36 & 0.33 \\
\hline 3 & 68 & 0.48 & 0.60 & 0.51 \\
\hline 4 & 106 & 0.37 & 1.00 & 1.02 \\
\hline 5 & 136 & 0.48 & 0.87 & 0.86 \\
\hline 6 & 204 & 0.48 & 1.45 & 1.45 \\
\hline 7 & 220 & 0.70 & 1.20 & 1.29 \\
\hline 8 & 313 & 0.57 & 2.20 & 2.29 \\
\hline 9 & 523 & 0.70 & -- & 2.9 \\
\hline
\end{tabular}

\section{RESULTS}

\section{Flame Height}

Flame heights were measured by videotape analysis and thermocouple measurements. Flame height determinations using videotape analysis used the $50 \%$ visual intermittency criterion for average flame height. Flame heights deduced from thermocouple measurements are based on the $500^{\circ} \mathrm{C}$ average centerline temperature criterion. The 
results of these measurements are shown in Table 1 . The videotape average flame heights and the $500^{\circ} \mathrm{C}$ definition of flame height agree very well for all tests except Test 3 where the difference was $0.1 \mathrm{~m}$.

Measurements of flame heights for square burners in the open and against a wall by Hasemi and Tokunaga ${ }^{19}$ showed that the presence of the wall does not measurably affect the flame height. Mizuno and Kawagoe ${ }^{20}$ have observed this same result for chair fires. As such, flame height correlations for flames in the open would be expected to be applicable to the present experimental results. Hasemi and Tokunaga ${ }^{21}$ have also shown that square and circular source flame heights correlate together if the source is characterized by the diameter or edge length for circular and square sources, respectively. Figure 2 shows the present flame height data compared to the flame height correlation of Heskestad $^{22}$. The correlation works well except for the two largest fires.

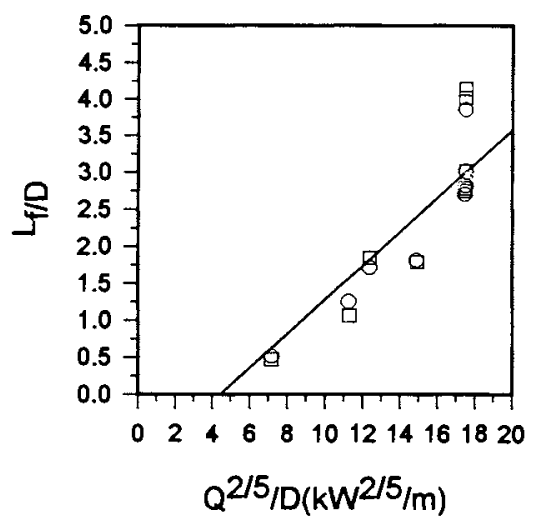

FIGURE 2. Comparison of experimentally determined flame heights with the Heskestad correlation. ${ }^{25}$ Circular symbols are based on videotape analysis, and square symbols are based on the height where the centerline average temperature was $500^{\circ} \mathrm{C}$.

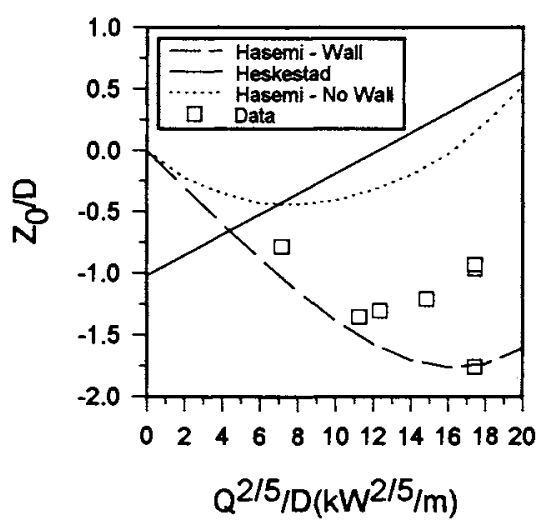

FIGURE 3. Comparison of experimentally determined virtual source heights with correlations for fires in the open (Heskestad ${ }^{25}$, Hasemi and Tokunaga ${ }^{21}$ ) and with the Hasemi and Tokunaga correlation for fire against walls.

\section{Virtual Source Location}

The virtual source location is a concept developed to allow real fire sources to be represented by point sources originating at a virtual origin for purposes of correlating properties in the plume region of a fire. Experimentally, the most direct method of determining the virtual source location is to plot $\left(\Delta T / Q^{2 / 3}\right)^{-3 / 5}$ versus the height of the $\Delta T$ 
plume temperature measurement $(Z)$. In such plots, the virtual source $\left(Z_{o}\right)$ is given by the $Z$ intercept. Positive values of $Z_{o}$ correspond to locations above the fuel source and negative below. While a number of virtual source correlations exist, there are few practical differences between them when compared to available data ${ }^{24}$. Figure 3 shows a comparison of the experimentally derived virtual source locations with the virtual source correlation of Heskestad ${ }^{25}$ derived for fires in the open and that of Hasemi and Tokunaga derived from data for fires against walls ${ }^{19}$ and in the open ${ }^{21}$. Since Hasemi and Tokunaga ${ }^{19}$ do not present the actual data used to develop their wall correlation, it is not possible to assess if the present data should be regarded as significantly different than their results. Clearly, however, the present results and trends are similar to their results for fires against walls and do not follow the non-wall correlations.

\section{Centerline Temperatures}

After adjusting the data for the experimental virtual source $\left(Z_{0}\right)$, the data appear to lie in two discrete regions, the flame and the plume, as compared to the three regions developed by McCaffrey ${ }^{26}$ (flame, intermittent, and plume). Although the experimental data are somewhat higher than estimated by McCaffrey, the equations developed for predicting the plume temperatures retain the same form. The temperatures in the flaming region are approximately constant $\left(900^{\circ} \mathrm{C}\right)$ in agreement with a large body of data for fires in the open and against walls ${ }^{24}$. The temperatures in the non-reactive zone decrease as a function of height and the energy release and are well represented by

$$
\Delta T_{C L}=40.6 \dot{Q}^{2 / 3}\left(Z-Z_{0}\right)^{-5 / 3} \quad\left(Z-Z_{0}\right) / \dot{Q}^{2 / 5}>0.16
$$

The experimental centerline temperatures are shown in Figure 4 along with Equation 1. Hasemi and Tokunaga ${ }^{19}$ developed a similar correlation for fires against walls and is represented by

$$
\Delta T_{C L}=43.0 \dot{Q}^{2 / 3}\left(Z-Z_{0}\right)^{-5 / 3} \quad\left(Z-Z_{0}\right) / \dot{Q}^{2 / 5}>0.18
$$

The $Q^{2 / 3} Z^{-5 / 3}$ dependence is in agreement with a large body of data for fires in the open and against walls ${ }^{24}$. The constant of proportionality is nearly twice that found for open plumes. Viewed collectively, the current temperature data are very consistent with existing results in the literature.

\section{Heat Flux}

The peak heat flux measurements for all the fires evaluated in this test series ranged from $40-120 \mathrm{~kW} / \mathrm{m}^{2}$. With the exceptions of the 300 and $500 \mathrm{~kW}$ fires, the peak heat flux occurred at the center line of the fire plume $15 \mathrm{~cm}$ above the sand burner surface. The two larger fires produced peak heat flux measurements at $30 \mathrm{~cm}$ above the burner. This is consistent with a cool recirculating region just above the fuel surface as is observed in many investigations of flame temperatures and gas species (e.g., Reference 23). 


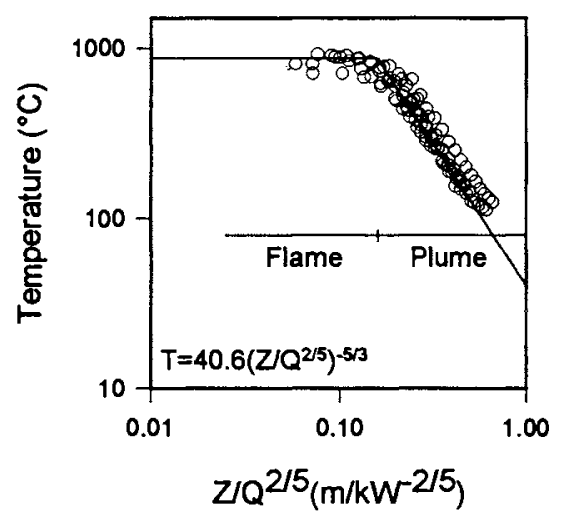

FIGURE 4. Centerline temperature rise correlation for all centerline data for the nine tests. The solid line is $900^{\circ} \mathrm{C}$ for $\left(\mathrm{Z}-\mathrm{Z}_{\mathrm{O}}\right) / \mathrm{Q}^{2 / 5}<0.16$ and follows Equation 1 above this region.

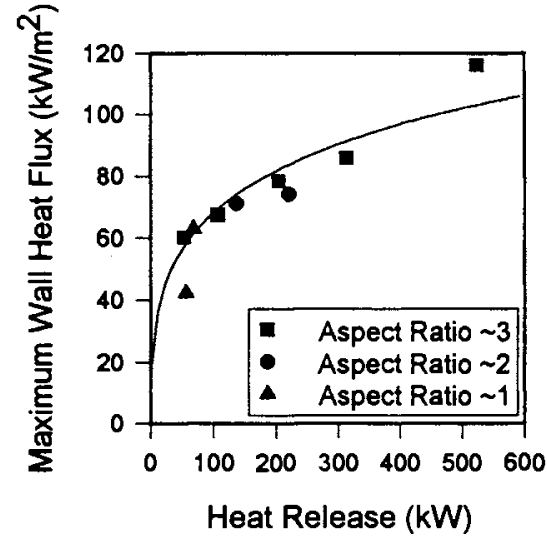

FIGURE 5. Correlation of the peak heat flux measured in the nine tests. Aspect ratio is defined as the flame height/burner edge length, $\mathrm{L}_{\mathrm{f}} \mathrm{D}$. The solid curve is Equation 4 with $\mathrm{E}=200$ $\mathrm{kW} / \mathrm{m}^{2}, \mathrm{k}_{\mathrm{a}}=0.09 \mathrm{~kW}^{-1 / 3}$.

The peak heat flux measurements for all tests are plotted versus heat release rate in Figure 5. The data suggest that for these size and shape fires, the peak heat flux is independent of the flame shape (aspect ratio, $\mathrm{L}_{\mathrm{f}}(\mathrm{D})$ and is only a function of energy release rate. The peak heat flux results can be modeled as radiatively dominated using a simple mean beam length approach. The peak heat flux, $q_{p}^{\prime \prime}$, can be expressed as the radiation from a grey emitting flame volume as

$$
\dot{q}_{p}^{\prime \prime}=E\left(1-\exp \left(-k L_{m}\right)\right)
$$

where $E$ is the blackbody emissive power of the flame, $\mathbf{k}$ is the extinction coefficient, and $\mathrm{L}_{\mathrm{m}}$ is the mean beam length. The mean beam length can be estimated from the heat release rate using the observation that the heat release per unit volume of flame is approximately constant. Recognizing that the mean beam length scales with the flame volume to the $1 / 3$ power yields

$$
\dot{q}_{p}^{\prime \prime}=E\left(1-\exp \left(-k_{g} \dot{Q}^{1 / 3}\right)\right)
$$

This provides a functional form for fitting the peak heat flux data shown in Figure 5 with two fitting constants, $E$ and $k_{\mathrm{a}}$. Fitting the data in Figure 5 yields $E=200 \mathrm{~kW} / \mathrm{m}^{2}$ and $\mathrm{k}_{\mathrm{a}}=0.09 \mathrm{~kW}^{-1 / 3}$. This curve is plotted in Figure 5. These fitting parameters are 
reasonable. $\mathrm{E}=200 \mathrm{~kW} / \mathrm{m}^{2}$ is typical of measured peak emissive powers ${ }^{27}$ and $\mathrm{k}_{\mathrm{a}}=$ $0.09 \mathrm{~kW}^{-1 / 3}$ is consistent with a value of $\mathrm{k}=1.31 / \mathrm{m}$ and a spherical flame geometry. The spherical flame geometry is obviously an oversimplified model, but is the only simple flame shape dependent on a single dimension as the data suggest is appropriate. A value of $\mathbf{k}=1.31 / \mathrm{m}$ is consistent with measurements by Markstein ${ }^{28}$ and by Orloff ${ }^{29}$.

The centerline measured heat flux profiles are shown in Figure 6 with the height normalized by the flame height. The flux is approximately equal to the peak flux over the lower $40 \%$ of the flame height and decays to $20 \mathrm{~kW} / \mathrm{m}^{2}$ at the flame height. The consistency of the $20 \mathrm{~kW} / \mathrm{m}^{2}$ incident flux at the flame height and its correspondence with a black body at $500^{\circ} \mathrm{C}$ are remarkable. Figure 7 shows the centerline data on a log plot where the behavior of the flame region can most clearly be seen. The slope of the plot is consistent with $\left(\mathrm{Z} / \mathrm{L}_{\mathrm{f}}\right)^{-5 / 3}$ dependence. The centerline heat flux is approximately constant over the lower $40 \%$ of the flame, decreases linearly to $20 \mathrm{~kW} / \mathrm{m}^{2}$ at the flame height, and decays according to the $5 / 3$ power of height above the flame. The centerline data can be represented by the following:

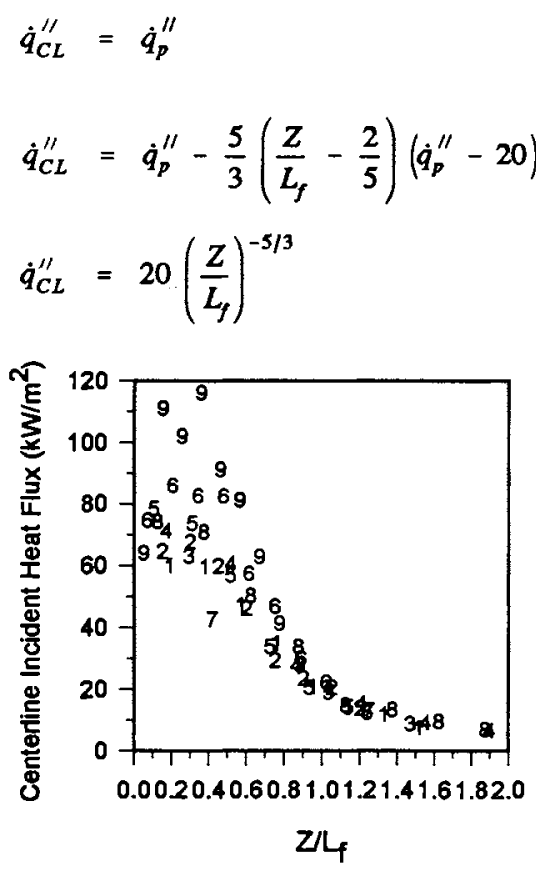

FIGURE 6. Correlation of the centerline heat flux with height, $\mathrm{Z}$, normalized by the flame height, $\mathrm{L}_{\mathrm{f}}$. Numbers refer to the test number in Table 1.

$$
\begin{aligned}
& \frac{Z}{L_{f}} \leq 0.4 \\
& 0.4<\frac{Z}{L_{f}} \leq 1.0 \\
& \frac{Z}{L_{f}}>1
\end{aligned}
$$

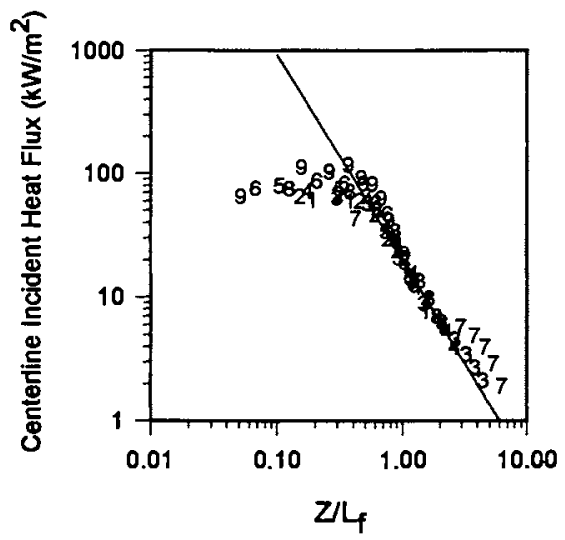

FIGURE 7. Semi-log plot of centerline heat flux data. The numbers refer to the test numbers in Table 1. The solid line is Equation $5 \mathrm{c}$. 
Correlation of the lateral heat flux distribution has been broken down into the flame and plume regions, i.e., above and below the average flame height. Both regions have been normalized by the centerline total heat flux at the measurement height. The lateral position has been normalized with the burner half length so that a normalized value of one corresponds to the edge of the fire source. The data in Figure 8 clearly show that the radiative heat fluxes beyond the edge of the source in many instances will be sufficient to allow lateral flame spread on the wall. This contrasts with line fire sources or wall sources, where the flames are very thin and radiate very little to the unignited lateral portions of the wall: The lateral heat flux distributions can be represented by

$$
\begin{array}{ll}
\dot{q}^{\prime \prime}=\dot{q}_{C L}^{\prime \prime} \exp \left(-\left(\frac{X}{0.5 D}\right)^{2}\right) & \frac{X}{0.5 D}<1.0 \\
\dot{q}^{\prime \prime}=0.38 \dot{q}_{C L}^{\prime \prime}\left(\frac{X}{0.5 D}\right)^{-1.7} & \frac{X}{0.5 D}>1.0
\end{array}
$$

The heat flux measurements above the flame are shown in Figure 9. While the general shape of the lateral profiles is as expected, the scatter in the data as correlation is

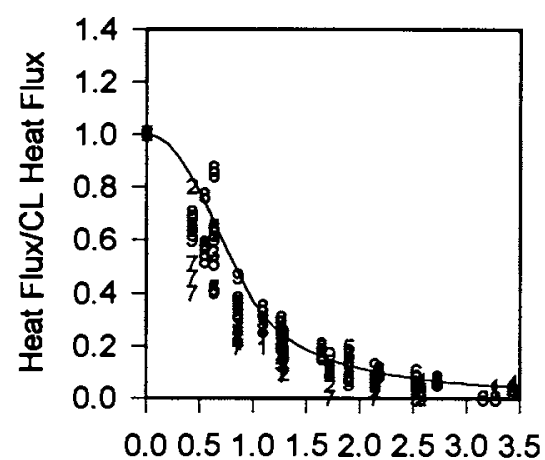

Distance/Burner Half Length

FIGURE 8. Correlation of the lateral heat flux distributions below the flame height. Heat flux, $q$ ", is normalized by the centerline heat flux, $\mathrm{q}_{\mathrm{CL}}$, and lateral distance, $X$, is normalized by the burner half length, 0.5D. Numbers refer to the Test number in Table 1 and the solid line is Equation 6. The plot includes approximately 300 data points.

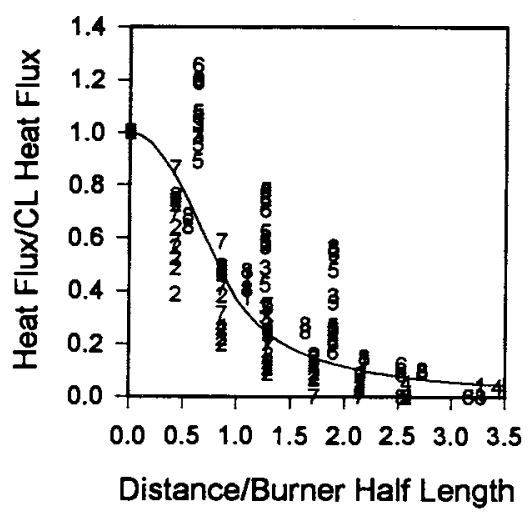

FIGURE 9. Correlation of the lateral heat flux distribution above the flame height. Heat flux, q", is normalized by the centerline heat flux, q" $\mathrm{CL}$, and lateral distance, $\mathrm{X}$, is normalized by the burner half length, $0.5 \mathrm{D}$. Numbers refer to the test number in Table 1 and the solid line is Equation 6. The plot includes approximately 200 data points. 
greater than in the flame region. This is both the result of the very low heat fluxes in this region and the inappropriateness of the radial normalizations used. The heat flux in this region is convectively dominated, and the normalizations chosen for the radiatively dominated region are not expected to work well in this region. Attempts to correlate this data using plume virtual source data did not result in any useful correlational results.

\section{DISCUSSION}

The results as correlated in Figures 5-9 form the basis for predicting the distribution of incident heat flux from a flame ignition source to an adjacent wall. This forms the initial conditions for the development of a flame on the wall and subsequent spread. On the basis of the maximum heat fluxes as shown in Figure 5 in the range $40-120 \mathrm{~kW} / \mathrm{m}^{2}$ for $50-500 \mathrm{~kW}$ fire sources, it is fair to observe that any combustible wall material would be expected to be ignited by any of the fires studied in this work. A $50 \mathrm{~kW}$ fire source gives rise to incident heat fluxes of around $50 \mathrm{~kW} / \mathrm{m}^{2}$. This heat flux exceeds the critical flux for piloted ignition of virtually any combustible material ${ }^{30}$.

This clearly changes the question from one of will the wall material become involved to one of will the wall material allow spread away from the area of direct flame contact. Given that the heat fluxes from adjacent item flames to a wall are much higher than wall or line fire sources, the approaches used to date based on wall or line fire sources are not expected to accurately assess flame spread on walls exposed to adjacent item flames.

\section{CONCLUSIONS}

Correlations of incident heat flux to a wall from an adjacent fire source have been developed which are suitable for integration into wall flame spread models. The data correlations show that the peak heat fluxes are dependent on the heat release rate and are in the range $50-120 \mathrm{~kW} / \mathrm{m}^{2}$ for fires in the range of $50-500 \mathrm{~kW}$. These fluxes are sufficient to ignite most combustible materials.

\section{REFERENCES}

1. Delichatsios, M.A. (1984), "Flame Heights in Turbulent Wall Fires with Significant Flame Radiation," Combustion Science and Technology, 39, 1984, pp. 195-214.

2. Delichatsios, M.A., Mathews, M.K., and Delichatsios, M.A. (1991), "An Upward Fire Spread and Growth Simulation," Fire Safety Science-Proceedings of the Third International Symposium, Elsevier Science Publishers, Ltd., 1991, pp. 207-216. 
3. Delichatsios, M.A., and Saito, K. (1991), "Upward Fire Spread: Key Flammability Properties, Similarity Solutions and Flammability Indices," Fire Safety Science-Proceedings of the Third International Symposium, Elsevier Science Publishers, Ltd., 1991, pp. 217-226.

4. Hasemi, Y. (1984), "Experimental Wall Flame Heat Transfer Correlations for the Analysis of Upward Wall Flame Spread," Fire Science and Technology, 4 (2), 1984, pp. 75-90.

5. Hasemi, Y. (1986), "Thermal Modeling of Upward Wall Flame Spread," Fire Safety Science-Proceedings of the First International Symposium, Hemisphere Publishing Corporation, NY, 1986, pp. 87-96.

6. Hasemi, Y., Yoshida, M., Nohara, A., and Nakabayashi, T. (1991), "UnsteadyState Upward Flame Spreading Velocity along Vertical Combustible Solid and Influence of External Radiation on the Flame Spread," Fire Safety Science-Proceedings of the Third International Symposium, Elsevier Science Publishers, Ltd., 1991, pp. 197-206.

7. Mitler, H.E. (1989), "Algorithm for the Mass-Loss Rate of a Burning Wall," Fire Safety Science-Proceedings of the Second International Symposium, Hemisphere Publishing Corporation, NY, 1989, pp. 179-188.

8. Saito, K., Quintiere, J.G., and Williams, F.A. (1986), "Upward Turbulent Flame Spread," Fire Safety Science-Proceedings of the First International Symposium, Hemisphere Publishing Corporation, NY, 1986, pp. 75-86.

9. Ahonen, A.I., Holmlund, C., and Kokkala, M.A. (1987), "Effects of Ignition Source in Room Fire Tests," Fire Science and Technology, 7 (1), 1987, pp. 1-13.

10. Cleary, T.G., and Quintiere, J.G. (1991), "A Framework for Utilizing Fire Property Tests," Fire Safety Science-Proceedings of the Third International Symposium, Elsevier Science Publishers, Ltd., 1991, pp. 647-656.

11. Karlsson, B. (1993), "A Mathematical Model for Calculating Heat Release Rate in the Room Corner Test," Fire Safety Joumal, 20, 1993, pp. 93-113.

12. Karlsson, B., and Magnusson, S.E. (1991), "Combustible Wall Lining Materials: Numerical Simulation of Room Fire Growth and the Outline of a Reliability Based Classification Procedure," Fire Safety Science-Proceedings of the Third International Symposium, Elsevier Science Publishers, Ltd., 1991, pp. 667-678.

13. Mowrer, F.W., and Williamson, R.B. (1991), "Flame Spread Evaluation for Thin Interior Finish Materials," Fire Safety Science-Proceedings of the Third International Symposium, Elsevier Science Publishers, Ltd., 1991, pp. 689-698. 
14. Newman, J.S., and Tewarson, A. (1991), "Flame Spread Behavior of CharForming Wall/Ceiling Insulating Materials," Fire Safety Science-Proceedings of the Third International Symposium, Elsevier Science Publishers, Ltd., 1991, pp. 679688.

15. Williamson, R.B., Revenaugh, A., and Mowrer, F.W. (1991), "Ignition Sources in Room Fire Tests and Some Implications for Flame Spread Evaluation," Fire Safety Science-Proceedings of the Third International Symposium, Elsevier Science Publishers, Ltd., 1991, pp. 657-666.

16. Kokkala, M.A., "Characteristics of a Flame in an Open Corner of Walls," Interflam '93, Interscience Communications Ltd., London, 1993, pp. 13-24.

17. Quintiere, J., Harkleroad, M., and Hasemi, Y., "Wall Flames and Implications for Upward Flame Spread," Combustion Science and Technology, 48, 1986, pp. 191222.

18. Mizuno, T., and Kawagoe, K. (1985), "Burning Behaviour of Upholstered Chairs: Part 2, Burning Rate of Chairs in Fire Tests," Fire Science and Technology, 5 (1), 1985, pp. 69-78.

19. Hasemi, Y., and Tokunaga, T. (1984), "Some Experimental Aspects of Turbulent Diffusion Flames and Buoyant Plumes from Fire Sources Against a Wall and in a Corner of Walls," Combustion Science and Technology, 40, 1984, pp. 1-17.

20. Mizuno, T., and Kawagoe, K. (1986), "Burning Behaviour of Upholstered Chairs: Part 3, Flame and Plume Characteristics in Fire Test," Fire Science and Technology, 6 (1), 1986, pp. 29-37.

21. Hasemi, Y., and Tokunaga, T. (1984), "Flame Geometry Effects on the Buoyant Plumes from Turbulent Diffusion Flames," Fire Science and Technology, 4 (1), 1984, pp. 15-26.

22. Heskestad, G., "Luminous Height of Turbulent Diffusion Flames," Fire Safety Joumal, 5, 1993, pp. 103-108.

23. Bouhafid, A., Vantelon, J.P., Joulain, P., and Fernandez-Pello, A.C. (1988), "On the Flame Structure at the Base of a Pool Fire," Twenty-Second Symposium (International) on Combustion, The Combustion Institute, 1988, pp. 1291-1298.

24. Beyler, C., "Fire Plumes and Ceiling Jets," Fire Safety Joumal, 11, 1986, pp. 53-75.

25. Heskestad, G., "Virtual Origins of Fire Plumes, Fire Safety Joumal, 5, 1983, p. 109.

26. McCaffrey, B., "Purely Buoyant Diffusion Flames: Some Experimental Results," NBSIR 79-1910, National Bureau of Standards, Gaithersburg, MD, 1979. 
27. Mudan, K.S., and Croce, P., "Fire Hazard Calculations for Large Open Hydrocarbon Fires," SFPE Handbook of Fire Protection Engineering, Chapter 2-4, National Fire Protection Association, Quincy, MA, 1988.

28. Markstein, G., "Radiative Properties of Plastic Fires," Seventeenth Symposium (International) on Combustion, The Combustion Institute, 1979, pp. 1053-1062.

29. Orloff, L., "Simplified Radiation Modeling of Pool Fires," Eighteenth Symposium (International) on Combustion, The Combustion Institute, 1981, pp. 549-561.

30. Quintiere, J.G., and Harkleroad, M.T., "New Concepts for Measuring Flame Spread Properties," Fire Safety: Science and Engineering. ASTM STP 882. T.Z. Harmathy, Ed., American Society for Testing and Materials, Philadelphia, PA, 1985, pp. 239-267.

\section{NOMENCLATURE}

$\mathrm{D}=$ Burner edge length, $\mathrm{m}$

$\mathrm{E}=$ Blackbody emissive power, $\mathrm{kW} / \mathrm{m}^{2}$

$\mathrm{k}=$ Flame extinction coefficient, $1 / \mathrm{m}$

$\mathrm{k}_{\mathrm{a}}=$ Fitting constant in Equation $4, \mathrm{~kW}^{-1 / 3}$

$\mathrm{L}_{\mathrm{f}}=$ Flame height, $\mathrm{m}$

$\mathrm{L}_{\mathrm{m}}=\quad$ Mean beam length of flame, $\mathrm{m}$

$\mathrm{Q}=$ Heat release rate, $\mathrm{kW}$

q" = Total incident heat flux to the wall, $\mathrm{kW} / \mathrm{m}^{2}$

$\mathrm{q}^{\prime \prime} \mathrm{p} \quad=$ Peak total incident heat flux to the wall, $\mathrm{kW} / \mathrm{m}^{2}$

$\mathrm{q}_{\mathrm{CL}}^{\prime \prime} \mathrm{p}=$ Centerline incident heat flux to the wall, $\mathrm{kW} / \mathrm{m}^{2}$

$\mathrm{X}=$ Lateral distance from burner centerline, $\mathrm{m}$

$\mathrm{Z}=$ Height above the burner, $\mathrm{m}$

$\mathrm{Z}_{\mathrm{o}}=$ Virtual source height relative to the burner, $\mathrm{m}$

$\Delta \mathrm{T}=$ Temperature rise, $\mathrm{K}$

$\Delta \mathrm{T}_{\mathrm{CL}}=$ Centerline temperature rise, $\mathrm{K}$ 